\title{
Terrestrial planet compositions controlled by accretion disk magnetic field
}

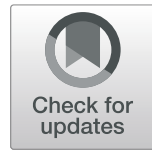

\author{
William F. McDonough 1,2,3* (1) and Takashi Yoshizaki ${ }^{2}$
}

\begin{abstract}
Terrestrial planets (Mercury, Venus, Earth, and Mars) are differentiated into three layers: a metallic core, a silicate shell (mantle and crust), and a volatile envelope of gases, ices, and, for the Earth, liquid water. Each layer has different dominant elements (e.g., increasing iron content with depth and increasing oxygen content to the surface). Chondrites, the building blocks of the terrestrial planets, have mass and atomic proportions of oxygen, iron, magnesium, and silicon totaling $\geq 90 \%$ and variable $\mathrm{Mg} / \mathrm{Si}(\sim 25 \%)$, Fe/Si (factor of $\geq 2$ ), and Fe/O (factor of $\geq 3$ ). What remains an unknown is to what degree did physical processes during nebular disk accretion versus those during postnebular disk accretion (e.g., impact erosion) influence these planets final bulk compositions. Here we predict terrestrial planet compositions and show that their core mass fractions and uncompressed densities correlate with their heliocentric distance, and follow a simple model of the magnetic field strength in the protoplanetary disk. Our model assesses the distribution of iron in terms of increasing oxidation state, aerodynamics, and a decreasing magnetic field strength outward from the Sun, leading to decreasing core size of the terrestrial planets with radial distance. This distribution enhances habitability in our solar system and may be equally applicable to exoplanetary systems.
\end{abstract}

Keywords: Planetary formation, Planetary composition, Accretionary disk, Magnetic field

\section{Introduction}

The formation of metallic cores in terrestrial planets greatly influences the thermal and biological evolution of a planet. Core formation typically concentrates the heat producing elements (i.e., potassium, thorium, and uranium) into the insulating, outer silicate shell and produces a conductive fluid, which can create a planetary magnetic field. The presence of a long-lived, internally convecting metallic core results in dynamo action and the generation of a planet's surrounding protective magnetosphere that nurtures life. These differentiated planets represent the most likely home for life and its evolution. Core segregation also controls the distribution of some essential nutrients (e.g., phosphorus) (e.g., 90\% of the Earth's P budget is in the core; McDonough, 2014). The mass

\footnotetext{
*Correspondence: mcdonoug@umd.edu

'Department of Geology, University of Maryland, College Park, 8000 Regents Drive, College Park, MD 20742, USA

2Department of Earth Science, Tohoku University, 6-3, Aoba, Aramaki, Aoba,

Sendai 980-8578, Japan

Full list of author information is available at the end of the article
}

fraction of metallic core in Mercury, Venus, Earth, and Mars decreases with heliocentric distance from about 3/4, to $1 / 3$ (Venus and Earth), to $1 / 5$, respectively (Sohl and Schubert 2015). Chondrites, the building blocks of the terrestrial planets, have $\geq 93 \%$ of their mass and atomic proportion being composed of $\mathrm{O}, \mathrm{Fe}, \mathrm{Mg}$, and $\mathrm{Si}$ (Wasson and Kallemeyn 1988). The abundances of $\mathrm{O}$ and $\mathrm{Fe}$ in chondrites typically varies by a factor of three, but in some uncommon Fe-rich examples, it approaches a factor of eight. In addition, most chondritic meteorites (except $\mathrm{EH}, \mathrm{G}, \mathrm{CB}$, and $\mathrm{CH}$ chondrite groups) have sub-solar Fe/ $\mathrm{Si}$ values (Urey and Craig 1953; Wood 2005). What chemical and/or physical processes produced the large variation observed in $\mathrm{Fe} / \mathrm{O}$ values in chondrites and the terrestrial planets, particularly for the dense, metal-rich planet Mercury?

Given the compositions of the terrestrial planets and chondritic asteroids, there was, on average, an outward
SpringerOpen
(C) The Author(s). 2021 Open Access This article is licensed under a Creative Commons Attribution 4.0 International License, which permits use, sharing, adaptation, distribution and reproduction in any medium or format, as long as you give appropriate credit to the original author(s) and the source, provide a link to the Creative Commons licence, and indicate if changes were made. The images or other third party material in this article are included in the article's Creative Commons licence, unless indicated otherwise in a credit line to the material. If material is not included in the article's Creative Commons licence and your intended use is not permitted by statutory regulation or exceeds the permitted use, you will need to obtain permission directly from the copyright holder. To view a copy of this licence, visit http://creativecommons.org/licenses/by/4.0/. 
increase in oxygen fugacity during their accretion. Likewise, in space and time, there was also a decrease in nebular condensation temperatures and amounts of metallic iron contributing to planetary building. We also note that the protoplanetary disk had redox and temperature gradients that lead to less metallic iron and more $\mathrm{H}$ - and O-rich solids (i.e., phyllosilicates) outward in the solar system. Importantly, equilibrium nebular condensates do not reach the high $\mathrm{Fe} / \mathrm{Si}$ values of Mercury even with strongly reduced, high-temperature conditions (Weidenschilling 1978; Cameron et al. 1988; Ebel and Alexander 2011). Thus, further metal-oxide separation processes, such as a mechanical enrichment of metal sunwards in the protoplanetary disk (Larimer and Anders 1970; Weidenschilling 1978; Wasson 1988; Wurm et al. 2013) and post-accretionary mantle stripping by one or multiple impacts (Benz et al. 1988; Cameron et al. 1988; Asphaug 2014), are needed to produce a dense planet like Mercury.

\section{The protoplanetary disk}

The terrestrial planets are the residua of the Sun's accretion, given the former's negligible mass contribution (a few parts per million) to the solar system. Stars and planets form from the gravitational collapse of a molecular cloud (McKee and Ostriker 2007). The shared rotational moments and prograde orbits of the Sun and planets document the solar system's formation from a co-rotational, accreting gas-dust cloud (i.e., a protoplanetary disk, or solar nebula). Protoplanetary disks are rapidly evolving systems with lifetimes of up to 10 million years (Myr) (Williams and Cieza 2011). Many physical and chemical attributes of the disk (i.e., temperature, redox state, composition, gas and solid density, magnetic field strength) change in both time and space. The dynamics of these processes help shape the composition of the planets and we highlight here a few critical variables that have played a role in building the terrestrial planets.

The dust comprising this molecular cloud is conventionally considered to be equivalent in composition to CI chondrite, the seemingly most primitive undifferentiated meteorite, whose composition best matches that of the solar photosphere (e.g., Asplund et al. (2009)). However, one cannot simply take this composition to make a planet without considering chemical fractionation accompanying the condensation process, which is well documented in the chondrites (Larimer and Anders 1970). The gravitational collapse of the molecular cloud, the rapid inflow of material onto the star accompanied by outflow of material to conserve the angular momentum, and the frictional heating of the disk during these processes, collectively produced a high-temperature gradient outwards from the Sun (Boss 1998). Thus, the high-temperature state of the inner collapsing disk vaporized the pre-existing materials, which in turn led to their re-condensing in a specific sequence recorded in minerals in chondrites (Larimer and Anders 1970).

The mineralogical and chemical compositions of the terrestrial planets and chondritic bodies reflect timeintegrated, local nebular conditions during their formation (Figs. 1 and 2). Chondrites and other meteorites document the spatial compositional heterogeneity in the solar system (Larimer 1979; Kerridge 1979; Warren 2011). Compositionally-driven models for the Earth's accretion conclude that there was a temporal variation in the chemistry of materials added to the growing planet. Earth's early accretion (i.e., as much as 60 to $90 \%$ of its mass) was dominated by reduced materials and the remainder by oxidized materials (Wänke 1981; Rubie et al. 2011; Dauphas 2017).

A redox gradient in the protoplanetary disk is documented in the chondrites (Righter et al. 2016). The more reduced, non-carbonaceous (NC) meteorites, including the enstatite and ordinary chondrites (Fig. 2), come from the inner solar system, closer to the Sun (i.e., inward of the Jupiter's orbit) (Kruijer et al. 2017). The more oxidized carbonaceous chondrites (CC) and related meteorites (Figs. 1 and 2) are considered to be from more distal sources, including the outer asteroid belt (e.g., $\geq 3 \mathrm{AU}$ ), Jupiter's Trojans, and the Kuiper belt (Kruijer et al. 2017). The redox state and a dozen or so isotopic systems now link enstatite chondrites and the Earth and equally, ordinary chondrites and Mars (Warren 2011; Dauphas 2017). The Earth at $1 \mathrm{AU}$ is more oxidized than the enstatite chondrites, but less so than Mars at 1.5 AU and the ordinary chondrites (Fig. 2b).

\section{Composition of the terrestrial planets}

Compositional models for the terrestrial planets are constructed from the following data sets: composition of the Sun (i.e., > 99\% mass of the solar system) (Lodders 2020), chemical trends for samples from a planet, satellite observations, and compositions of chondritic meteorites (i.e., the solar system's building blocks of undifferentiated rock and metal mixtures) (Wasson and Kallemeyn 1988; Alexander 2019a; 2019b). Importantly, the chondrites that we have, however, are leftovers from the planetary formation. The bulk compositions of chondrites can be broken down into main group (i.e., $\mathrm{O}, \mathrm{Mg}, \mathrm{Si}$, and $\mathrm{Fe}$; $\sim 93 \%$ ) and minor group elements (i.e., $\mathrm{Al}, \mathrm{Ca}, \mathrm{S}$, and $\mathrm{Ni}$ ) and together they constitute $99 \%$ the mass and atomic proportions of all terrestrial planetary models (Fig. 1 and Table 1).

Here we use our earlier compositional models for the Earth (McDonough 2014) and Mars (Yoshizaki and McDonough 2020) and model the recent data from the MESSENGER mission to Mercury (Margot et al. 2018; Nittler et al. 2018) to predict its bulk composition (Table 1), which is verified to be consistent 


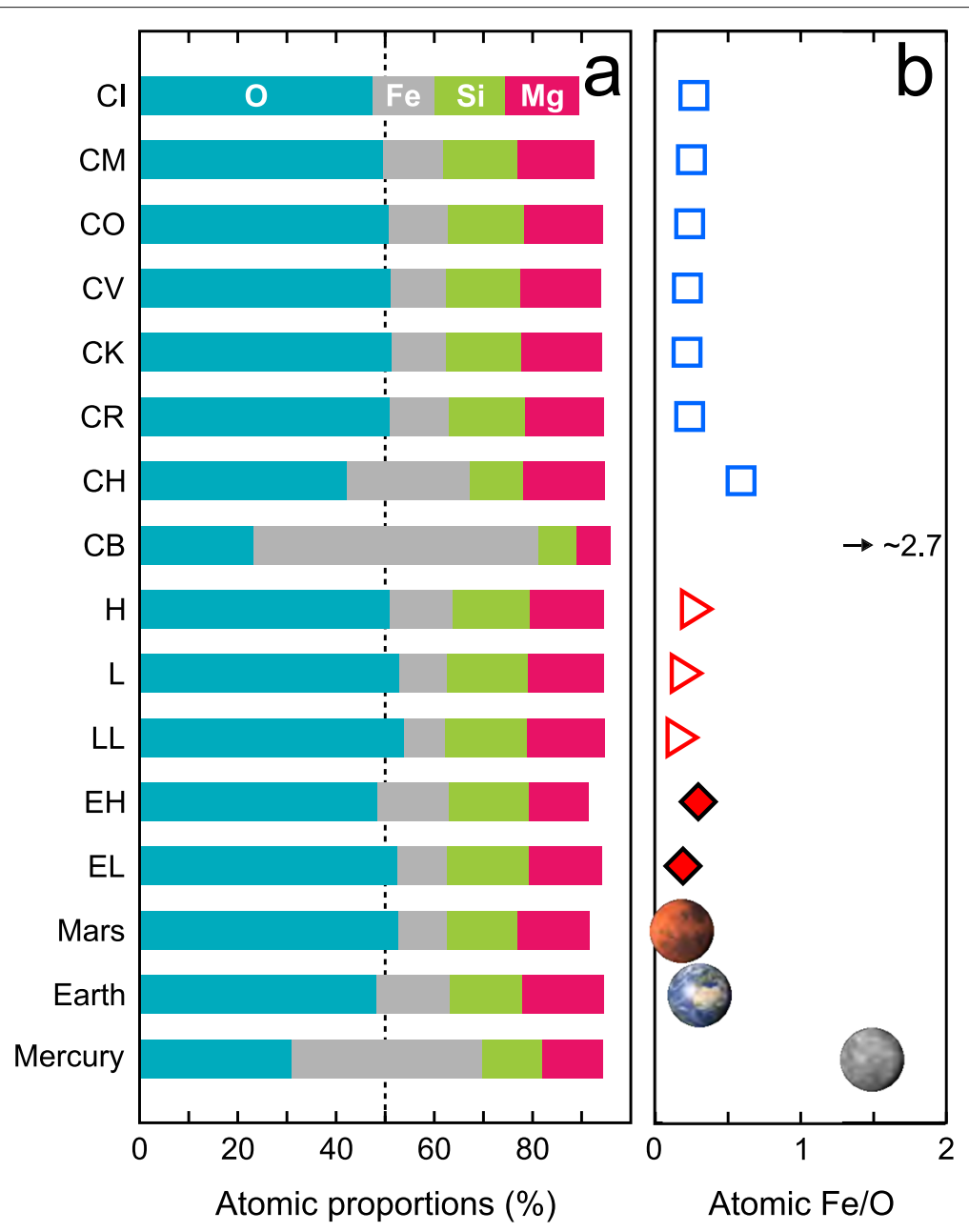

Fig. 1 a Atomic abundances of major elements and b Fe/O values in the solar system bodies. Data sources: chondrites (Alexander 2019a; 2019b; McCall 1968; Ivanova et al. 2008; Gosselin and Laul 1990; Wasson and Kallemeyn 1990; Bischoff et al. 1993); Mercury (this study); Earth (McDonough 2014); Mars (Yoshizaki and McDonough 2020)
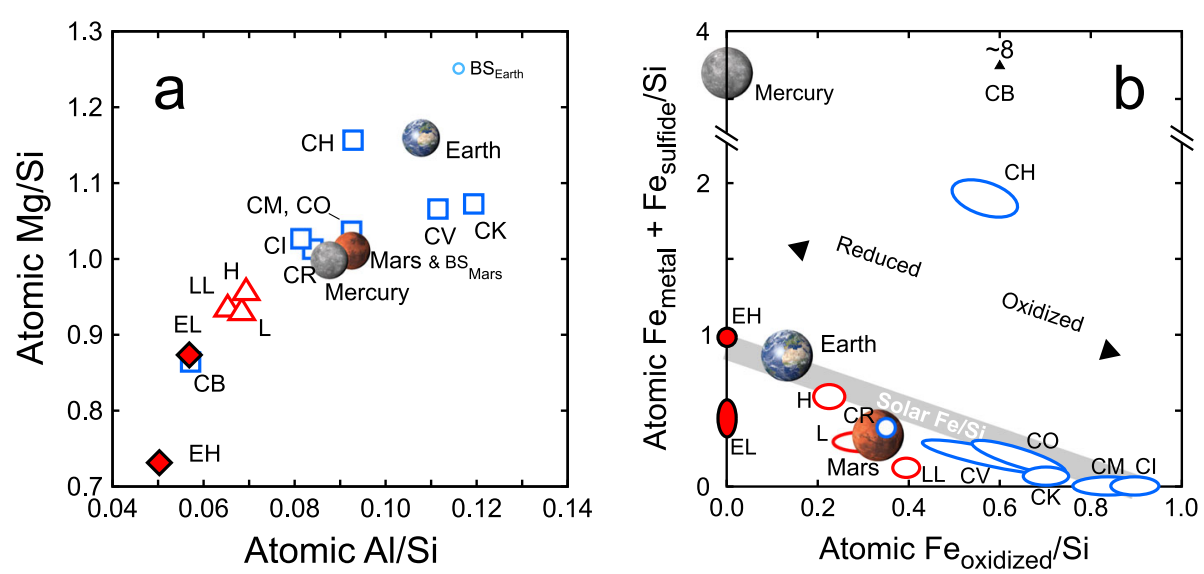

Fig. 2 Ratios of major cations in the terrestrial planets and chondrites. a Magnesium/Si versus Al/Si. b Abundances of reduced (metal and sulfide) and oxidized Fe normalized to Si. Data sources are as in Fig. 1 and Urey and Craig (1953). Red symbols identify the inner solar system, NC chondrites; see text for details. The Si-bearing core results in a Bulk Silicate Mercury that plots off scale at Al/Si (0.143) and Mg/Si (1.53) 
Table 1 Composition of the terrestrial planets

\begin{tabular}{|c|c|c|c|c|c|}
\hline Atomic\% & Mercury $^{a}$ & Venus $^{a}$ & Earth $^{b}$ & Mars $^{c}$ & $\begin{array}{l}\mathrm{Cl}_{\text {chondrite }}{ }^{d} \\
\text { (volatile-free) }\end{array}$ \\
\hline O & 27.5 & 49.0 & 49.0 & 55.3 & 48.2 \\
\hline $\mathrm{Mg}$ & 11.1 & 16.7 & 16.7 & 15.3 & 15.1 \\
\hline $\mathrm{Si}$ & 11.1 & 15.1 & 15.1 & 15.1 & 14.7 \\
\hline $\mathrm{Fe}$ & 41.2 & 15.1 & 15.1 & 10.3 & 12.8 \\
\hline $\mathrm{Ni}$ & 2.25 & 0.82 & 0.82 & 0.57 & 0.70 \\
\hline $\mathrm{Al}$ & 1.03 & 1.56 & 1.56 & 1.41 & 1.20 \\
\hline $\mathrm{Ca}$ & 0.75 & 1.13 & 1.13 & 1.03 & 0.88 \\
\hline S & 5.07 & 0.52 & 0.52 & 0.92 & 6.43 \\
\hline $\mathrm{Fe} / \mathrm{O}$ & 1.50 & 0.31 & 0.31 & 0.19 & 0.27 \\
\hline $\mathrm{Fe} / \mathrm{Si}$ & 3.71 & 1.00 & 1.00 & 0.69 & 0.87 \\
\hline $\mathrm{Mg} / \mathrm{Si}$ & 0.99 & 1.11 & 1.11 & 1.02 & 1.03 \\
\hline $\mathrm{Al} / \mathrm{Si}$ & 0.093 & 0.103 & 0.103 & 0.093 & 0.082 \\
\hline $\mathrm{Fe} / \mathrm{Al}$ & 40.0 & 9.7 & 9.7 & 7.3 & 10.7 \\
\hline $\mathrm{Mg} / \mathrm{Al}$ & 10.7 & 10.8 & 10.8 & 10.9 & 12.6 \\
\hline mean $Z$ & 17.5 & 12.7 & 12.7 & 11.8 & 12.6 \\
\hline$w t \%$ & Mercury & Venus & Earth & Mars & $\mathrm{Cl}$ (volatile-free) \\
\hline O & $12.0( \pm 2.1)$ & 29.7 & 29.7 & 36.3 & 29.1 \\
\hline $\mathrm{Mg}$ & $7.31( \pm 1.3)$ & 15.4 & 15.4 & 15.3 & 13.9 \\
\hline $\mathrm{Si}$ & $8.50( \pm 1.0)$ & 16.1 & 16.1 & 17.4 & 15.6 \\
\hline $\mathrm{Fe}$ & $62.6( \pm 4.5)$ & 32.0 & 32.0 & 23.7 & 26.9 \\
\hline $\mathrm{Ni}$ & $3.60( \pm 0.25)$ & 1.82 & 1.82 & 1.36 & 1.54 \\
\hline $\mathrm{Al}$ & $0.76( \pm 0.14)$ & 1.59 & 1.59 & 1.56 & 1.22 \\
\hline $\mathrm{Ca}$ & $0.82( \pm 0.15)$ & 1.71 & 1.71 & 1.69 & 1.33 \\
\hline S & $4.42( \pm 1.50)$ & 0.64 & 0.64 & 1.21 & 7.78 \\
\hline Uncompressed $\rho^{e}$ & $5200 \pm 200$ & 4100 & 4200 & 3800 & $2430^{f}$ \\
\hline Metal mass fraction & $74 / 100( \pm 5)$ & $1 / 3$ & $1 / 3$ & $1 / 5$ & 0 \\
\hline $\mathrm{H}$ distance (AU) & 0.39 & 0.72 & 1.00 & 1.52 & $>15^{9}$ \\
\hline$h\left(\mathrm{pW} \mathrm{kg}{ }^{-1}\right)^{h}$ & 2.0 & 3.6 & 3.3 & 4.0 & - \\
\hline$h(\mathrm{TW})^{h}$ & 0.7 & 18 & 20 & 2.5 & - \\
\hline
\end{tabular}

${ }^{a}$ This study. The \pm values (1 standard deviation) are calculated as the differences between the high and low uncompressed density models

${ }^{b}$ McDonough (2014).

'Yoshizaki and McDonough (2020).

${ }^{\mathrm{d}}$ Alexander (2019a).

eUncompressed $\rho$, density, in kg/m³ (Lewis 1972; Lodders and Fegley Jr. 1998; Stacey 2005).

fMacke et al. (2011).

${ }^{9}$ Desch et al. (2018)

${ }^{h}$ Heat production in the bulk silicate planets are calculated from chondritic $(\mathrm{Al} / \mathrm{Th})_{\text {mass }}=2.81 \times 10^{5}$ and $(\mathrm{Th} / \mathrm{U})_{\text {mass }}=3.7$, planetary $(\mathrm{K} / \mathrm{Th})_{\text {mass }}=7000,3700$, and 5300 for Mercury, Earth, and Mars, respectively (Peplowski et al. 2011; Arevalo Jr. et al. 2009; Taylor et al. 2006), and an equation from McDonough et al. (2020). pW = 10 ${ }^{-12}$ W; TW $=$ $10^{12} \mathrm{~W}$.

with known physical and chemical constraints. Given limited data for Venus, which is consistent with an Earth-like analog (Surkov et al. 1987; Aitta 2012; Dumoulin et al. 2017), we assume it has a bulk Earth composition.

\subsection{Mercury model}

The bulk composition (i.e., abundant elements $\mathrm{O}, \mathrm{Fe}, \mathrm{Mg}$, $\mathrm{Si}, \mathrm{Ni}, \mathrm{Al}, \mathrm{Ca}$, and S) of Mercury was defined to be consistent with its geodetic observables: mass, density, and 
MOI (moment of inertia) (Margot et al. 2018), compositional trends for Earth and Mars, and chondritic ratios showing limited variation $(\leq \pm 10 \%)$. We used the density of Mercury and assumed a thermal gradient in the protoplanetary disk outward from the accreting Sun to constrain the model. Also, we assume chondritic proportions of $\mathrm{Ca} / \mathrm{Al}(0.73)$ and $\mathrm{Fe} / \mathrm{Ni}$ (18.3), which is empirically defined and reflects condensation conditions in the protoplanetary disk. (Unless otherwise specified, atomic ratios are reported throughout.)

Given a thermal gradient in the protoplanetary disk and higher condensation temperature for forsterite $\left(\mathrm{Mg}_{2} \mathrm{SiO}_{4}\right)$ versus enstatite $\left(\mathrm{Mg}_{2} \mathrm{Si}_{2} \mathrm{O}_{6}\right)$ (e.g., (Lodders 2003)), we predict a gradient in $\mathrm{Mg} / \mathrm{Si}$ and $\mathrm{Al} / \mathrm{Si}$ values from Mercury to Mars for the silicate component of these planets (Fig. 2). The major elements ( $\mathrm{Mg}, \mathrm{Fe}$, and $\mathrm{Si}$, plus $\mathrm{Ni}$ ) have lower condensation temperatures than the refractories $(\mathrm{Ca}, \mathrm{Al})$ and higher than the moderately volatiles (K and S). Prior studies (Larimer 1979; Kerridge 1979) have observed that $\mathrm{NC}$ chondrites form a distinctive array on the $\mathrm{Mg} / \mathrm{Si}-\mathrm{Al} / \mathrm{Si}$ plot as compared to CC meteorites (Fig. 2). Despite the marked variation in $\mathrm{Mg} / \mathrm{Si}$ and $\mathrm{Al} / \mathrm{Si}$ in chondrites, there is only $15 \%$ variation in $\mathrm{Mg} / \mathrm{Al}(11.2 \pm 1.7)$. Consequently, we assume a $\mathrm{Mg} / \mathrm{Al}$ (10.7) value for Mercury, which is comparable to that for Earth and Mars (10.8 \pm 0.1$)$ (Fig. 2).

We calculated Mercury's core and mantle fractions to be consistent with its uncompressed density (Table 1). The observed $\mathrm{Mg \#}$ (atomic $\mathrm{Mg} /(\mathrm{Mg}+\mathrm{Fe})$ ) of $\sim 0.99$ for Mercury's surface (Nittler et al. 2018) points to the core's differentiation proceeding under reducing conditions. Thus, some Si was likely added to the core (Nittler et al. 2018). Using the $\mathrm{Fe}-\mathrm{Ni}-\mathrm{Si}$ composition of kamacite ( $\mathrm{Fe}, \mathrm{Ni}$ alloy) and perryite $\left((\mathrm{Ni}, \mathrm{Fe})_{8}(\mathrm{Si}, \mathrm{P})_{2}\right)$ in enstatite chondrites as a guide, we assume the equivalent metal in Mercury to have $\mathrm{Fe} / \mathrm{Ni}$ of $18.3, \sim 4 \%$ atomic $\mathrm{Si}$, and $\mathrm{Ni} / \mathrm{Si} \sim 0.6$ (Ringwood 1961; Leitch and Smith 1982; Weisberg and Kimura 2012). The contribution of Si from a schreibersite $\left((\mathrm{Fe}, \mathrm{Ni})_{3} \mathrm{P}\right)$ component is not significant, given its low Si abundance $(\leq 0.2 \mathrm{wt} \%)$ and minor mode proportion $(\leq 1 \%)$ observed in type- 3 enstatite chondrites (Weisberg and Kimura 2012). The mantle is assumed to have a composition that is approximately that of an orthosilicate (pseudo-olivine), with cations of $\mathrm{Mg}, \mathrm{Al}, \mathrm{Ca}, \mathrm{Fe}$, and $\mathrm{Si}$, where $\mathrm{Ca} / \mathrm{Al}=0.73, \mathrm{Mg} / \mathrm{Al}=10.7$ and $\mathrm{Mg} \#=0.99$ and fitting $\mathrm{Si}$ to the remainder.

To model Mercury's interior we used the average densities of silicates, metals, and sulfides as 3300,7100 , and $4600 \mathrm{~kg} \mathrm{~m}^{-3}$, respectively, and obtained a mode proportion of 41:45:14, respectively. The resulting mass model for Mercury has $26 \pm 5 \%$ silicate shell and $74 \pm 5 \%$ core. This estimate compares favorably with that presented by Margot et al. (2018) for his Preliminary Reference Mercury Model (PRMM; 74\% core and 26\% silicate sphere).
Mercury's sulfur content was based on the planetary volatility trend established from its surface measured K/Th value (6000 to 8000 ) (in wt ratio; Nittler et al. (2018)), the Ni-normalized volatility trend for the siderophile and chalcophile elements established by Wasson and Kallemeyn (1988), and an extrapolation to the condensation temperature, following the practice used in McDonough and Sun (1995) and Yoshizaki and McDonough (2020). We adopted the 50\% condensation temperature of $\mathrm{S}$ in a gas of solar composition (Lodders 2003). The major carrier of $S$ in enstatite chondrites and possibly Mercury is troilite (FeS), which condenses at similar temperatures in both solar-like and highly reduced redox conditions (Hutson and Ruzicka 2000; Pasek et al. 2005). We note, however, that $S$ can become less volatile under highly reducing conditions because of stabilization of refractory sulfides such as oldhamite $(\mathrm{CaS})$ and $(\mathrm{MgS})$ and incorporation of refractory elements (e.g., $\mathrm{Ti}, \mathrm{Nb}$ ) into troilite (Hutson and Ruzicka 2000; Pasek et al. 2005; Yoshizaki et al. 2021). We referenced Mercury's volatile depleted $\mathrm{S}$ content to the average depletion factor of $\mathrm{K}$ (i.e., $\mathrm{K} / \mathrm{Th} \sim 7000$; $(\mathrm{K})_{\mathrm{CI}-\text { and } \mathrm{Al}-\text { normalized }} \sim 0.38$ ). Ratios of alkali metals to refractory elements provide an additional constraint on a planet's volatile element depletion trend, however, this simple model can be influenced by redox conditions and core formational processes. We estimate a sulfur content for Mercury of $4.4 \pm 1.5 \mathrm{wt} \%$. By comparison, Namur et al. (2016) has suggested the bulk Mercury has $3 \mathrm{wt} \%$ to $5 \mathrm{wt} \% \mathrm{~S}$, whereas Boujibar et al. (2019) has modeled a range of bulk $S$ contents based upon a range of plausible redox states $\left(\sim 23 \mathrm{wt} \% \mathrm{~S}\right.$ for $\log f_{\mathrm{O}_{2}}=$ IW -7 to $\sim 2 \mathrm{wt} \% \mathrm{~S}$ for IW -2.6 ) for the planet.

Mercury has a markedly elevated Fe and Ni abundances relative to its budget of lithophile elements (e.g., Fe/Al $=40.0, \mathrm{Fe} / \mathrm{Si}=3.7, \mathrm{Fe} / \mathrm{O}=1.5$; Table 1) leading to an

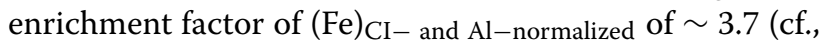
that for $\mathrm{Si}$ and $\mathrm{Mg}$ is 0.85 ). In addition, its $\mathrm{Mg} / \mathrm{Si}(0.99)$ is approximately CI-like, which is much higher than that for the highly reduced enstatite chondrites. This result is a product of our modeling approach that matches the planet's uncompressed density to the mode of silicate, $\mathrm{Fe}$ $\mathrm{Ni}-\mathrm{Si}$ metal, and troilite. Predicting Mercury's abundances of $\mathrm{S}$ and other chalcophile elements is challenging; it is the least volatile depleted body of the terrestrial planets (i.e., highest K/Th value). Our prediction of Mercury's S content (Fig. 3) is consistent with either (1) an extension of the volatile depletion trend for the siderophile elements, and/or (2) Mercury having CI relative abundances for elements with half-mass condensation temperatures of $<1000$ K (Krähenbühl et al. 1973; Takahashi et al. 1978; Braukmüller et al. 2019).

This temperature of $1000 \mathrm{~K}$ represents a limit. At lower temperatures in a condensing nebula, depending upon its $\mathrm{C} / \mathrm{O}$ value, precipitation of $\mathrm{MgS}$ and $\mathrm{CaS}$ phases begin 


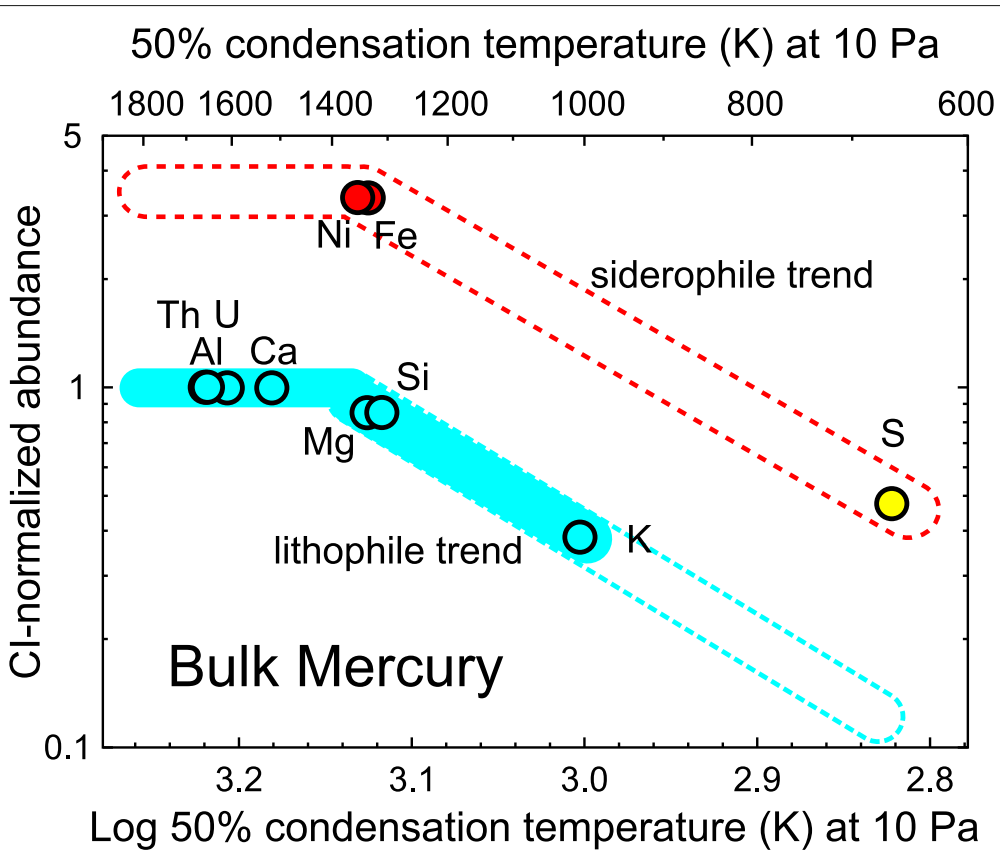

Fig. 3 Normalized abundances of the lithophile (blue) and siderophile (red) elements in the bulk Mercury. Abundances are normalized to Al and Cl chondrites and plotted against log of their 50\% condensation temperatures (K) at $10 \mathrm{~Pa}$ (see Yoshizaki and McDonough (2020)). Volatility trend for Mercury constrains its S content in the core. The predicted S content is consistent with either an extension of the volatile trend for the siderophile and/or and addition of $\mathrm{Cl}$ chondritic volatiles with $50 \%$ condensation temperatures $<1000 \mathrm{~K}$. See text for details

(Hutson \& Ruzicka, 2000). The consequence of significant $\mathrm{CaS}$ fractionation would result in changes to critical chondritic ratios (e.g., $\mathrm{Ca} / \mathrm{Al}, \mathrm{Ca} / \mathrm{Ti}$, and $\mathrm{Al} / \mathrm{Ti})$. Observations from the orbiting spectrometers on the MESSENGER Mission did not find such unusual ratios (Nittler et al., 2018). In contrast, chondrules from enstatite chondrites, which contain highly reduced silicates, are highly fractionated in both $\mathrm{Al} / \mathrm{Ti}$ and $\mathrm{Ca} / \mathrm{Al}$. Above this critical temperature of $1000 \mathrm{~K}$ condensation of fosterite and $\mathrm{Fe}-\mathrm{Ni}-\mathrm{Si}$ metal occurs, without accompanying sulfide precipitation. The result of these conditions is a bulk condensate with a $\mathrm{Mg} / \mathrm{Si}$ value that is higher than in enstatite chondrites and $\mathrm{Si}$-enriched metals; these are the features proposed for our model Mercury composition.

In Table 2, we present compositional models for the cores and bulk silicate shells of Mercury, Earth and Mars. The models for the Earth comes from McDonough (2014) and Mars from Yoshizaki and McDonough (2020). The model for Mercury is based on its bulk compositional model (Table 1) along with the following constraints: (1) $\mathrm{Mg}, \mathrm{Al}$, and $\mathrm{Ca}$ is solely concentrated in the silicate shell, (2) $\mathrm{Ni}$ and $\mathrm{S}$ is partition between the core (60\%, including and FeS component) and silicate shell (40\%) following the models of Namur et al. (2016) and Boujibar et al. (2019), (3) the silicate shell's Mg\# $=0.99$, (4) the Si contents of metals in $\mathrm{EH}$ chondrites, and (5) Si being partitioned between the core (35\%) and the silicate shell (65\%).

\subsubsection{Implications of the model}

Incorporation of silicon, sulfur, and other elements into the Fe-Ni core of Mercury influences its size, density, and solidus temperature. Lowering the solidus of the core keeps it molten and convecting, thus providing the critically important conditions for dynamo action and magnetosphere generation (Schubert et al. 1988; Tosi et al. 2013). Magnetospheres of terrestrial planets deflect solar wind particles. This deflection shield is important for a planet's atmospheric retention (i.e., losses due to radiation and solar winds), keeping water present at the surface, and protection of its biological habitat (See et al. 2014).

Based on the compositional estimates given in Table 1, chondritic ratios of refractory elements, and planetary $\mathrm{K} / \mathrm{Th}$ values, we have calculated the present-day radiogenic heating rate $\left(\mathrm{pW} \mathrm{kg} \mathrm{kg}^{-1}\right)$ and total planetary radiogenic power (TW) according to the method outlined in McDonough et al. (2020). The estimated bulk uranium contents of Mercury, Earth, and Mars are 7, 13, and $15 \mathrm{ppb}\left(10^{-9} \mathrm{~kg} / \mathrm{kg}\right)$. Because of its small fraction of silicate shell, Mercury has the least amount of total radiogenic power of the terrestrial planets (Table 1).

\section{Distribution of $\mathrm{Fe}$ (and $\mathrm{Ni}$ ) in the protoplanetary disk}

The Fe content of chondrites typically ranges from $1 / 5$ to $<1 / 3$ of their total mass, with Fe/Si typically $0.74 \pm 0.12$, 
Table 2 Composition of silicate shells and metallic cores of the terrestrial planets

\begin{tabular}{|c|c|c|c|}
\hline & Mercury ${ }^{a}$ & Earth $^{b}$ & Mars $^{c}$ \\
\hline \multicolumn{4}{|c|}{ Bulk silicate shell, atomic\% (wt\%) } \\
\hline O & $55.30(42.3)$ & $58.5(44.0)$ & $59.3(43.2)$ \\
\hline $\mathrm{Mg}$ & $25.93(25.9)$ & $20.0(22.8)$ & $16.9(18.7)$ \\
\hline $\mathrm{Si}$ & $14.6(19.6)$ & $15.9(21.0)$ & $16.6(21.3)$ \\
\hline $\mathrm{Fe}$ & $0.17(0.46)$ & $2.4(6.3)$ & $4.5(11.4)$ \\
\hline $\mathrm{Al}$ & $2.1(2.7)$ & $1.85(2.35)$ & $1.55(1.90)$ \\
\hline $\mathrm{Ca}$ & $1.5(2.9)$ & $1.34(2.53)$ & $1.13(2.06)$ \\
\hline$S$ & $4.1(6.3)$ & - & - \\
\hline Mg\# & 0.99 & 0.89 & 0.79 \\
\hline $\mathrm{Mg} / \mathrm{Si}$ & $1.53(1.32)$ & $1.26(1.09)$ & $1.01(0.88)$ \\
\hline $\mathrm{Al} / \mathrm{Si}$ & $0.143(0.137)$ & $0.117(0.11)$ & $0.0929(0.089)$ \\
\hline $\mathrm{Fe} / \mathrm{Si}$ & $0.0118(0.024)$ & $0.150(0.30)$ & $0.269(0.54)$ \\
\hline Silicate mass $(\mathrm{kg})^{d}$ & $8.6 \times 10^{22}$ & $4.04 \times 10^{24}$ & $5.27 \times 10^{23}$ \\
\hline \multicolumn{4}{|c|}{ Core, including an FeS component, atomic\% (wt\%) } \\
\hline O & - & $6.4(2.0)$ & $16(5.2)$ \\
\hline Si & $7.6(4.1)$ & $7.3(4.0)$ & - \\
\hline $\mathrm{Fe}$ & $81(86)$ & $78(86)$ & $68(80)$ \\
\hline $\mathrm{Ni}$ & $4.4(4.9)$ & $4.4(5.1)$ & $6.0(7.4)$ \\
\hline S & $6.0(3.6)$ & $3.0(1.9)$ & $9.9(6.6)$ \\
\hline
\end{tabular}

Values outside and inside parentheses are in atomic\% and wt\%, respectively

aThis study.

${ }^{b}$ McDonough (2014).

'Yoshizaki and McDonough (2020).

dPlanet masses from https://nssdc.gsfc.nasa.gov/planetary/factsheet/. Bulk silicate shell fractions are 0.260, 0.676, 0.820 for Mercury, Earth and Mars, respectively

whereas some rare chondrite groups (i.e., $\mathrm{CB}, \mathrm{CH}$, and $\mathrm{G}$ types) can have $\mathrm{Fe} / \mathrm{Si}$ values up to 8 (Fig. $2 \mathrm{~b}$ ). Our model for the terrestrial planets have $\mathrm{Fe} / \mathrm{Si}$ varying from 3.7 to 0.7 from Mercury to Mars (Table 1). The ratio of metallic iron to total iron varies from 1 (EH and EL chondrites) to $0(\mathrm{CI}$ and $\mathrm{CM})$ in the chondrites, whereas the terrestrial planets have intermediate values (Fig. $2 \mathrm{~b}$ and Table 1 ).

The amount of iron accreted by a chondritic parent body or a terrestrial planet is not set by any particular rule and likewise the same is true for its metal to oxide fraction. A planet's mass fraction of metallic core to silicate shell reflects the time-integrate redox condition during accretion and core-mantle differentiation. Impact-induced erosion/evaporation can also modify a core's mass fraction (Cameron et al. 1988). Accretion sets the relative contents of $\mathrm{Fe} / \mathrm{O}, \mathrm{Fe} / \mathrm{Si}, \mathrm{Fe} / \mathrm{Mg}$, and $\mathrm{Mg} / \mathrm{Si}$, which accounts for $\sim 93 \%$ of its mass (Fig. 1).

Mercury has the largest metallic core fraction, high $\mathrm{Fe} / \mathrm{Al} \mathrm{(40)}$ and $\mathrm{Mg} / \mathrm{Si}$ (0.99) values (Table 1 and Fig. 2), and a silicate sphere with negligible Fe (i.e., $\mathrm{Mg} \# \sim 0.99$ ) (Nittler et al. 2018). By comparison, Mars has a smaller metallic core, a lower Fe/Al (7.3) and $\mathrm{Mg} / \mathrm{Si} \mathrm{(1.02),} \mathrm{and} \mathrm{a}$ silicate shell with a low Mg\# (0.79) than Mercury and the
Earth $(9.7,1.11$, and 0.89 , respectively) (Table 1$)$. Therefore, in relative terms the silicate shells of Mars, Earth (and Venus), and Mercury get progressively thinner, their cores bigger, and their mantles more Mg\#-rich with decreasing heliocentric distance.

Here we show that the uncompressed densities (Fig. 4) and mean atomic numbers $(Z$, Table 1$)$ of the terrestrial planets increases with decreasing heliocentric distance. These trends also extend to bodies in the asteroidal belt: undifferentiated and differentiated asteroids are less dense than the terrestrial planets (Fig. 4). Most chondrites have sub-solar Fe/Si (Fig. 2b) and show a marked variation in $\mathrm{Fe} / \mathrm{Si}$ and metallic iron content. Thus, the outward decrease of planetary density appears to primarily reflect dynamic metal-oxide separation in the protoplanetary disk, rather than post-accretionary processes.

\section{Processes in the protoplanetary disk}

Significantly, condensing iron-nickel grains, and other metallic alloys, in the protoplanetary disk are distinctly influenced by aerodynamic, gravitational, photophoretic, and electromagnetic sorting forces, compared to silicates (Larimer and Anders 1970; Weidenschilling 1978; Wurm 


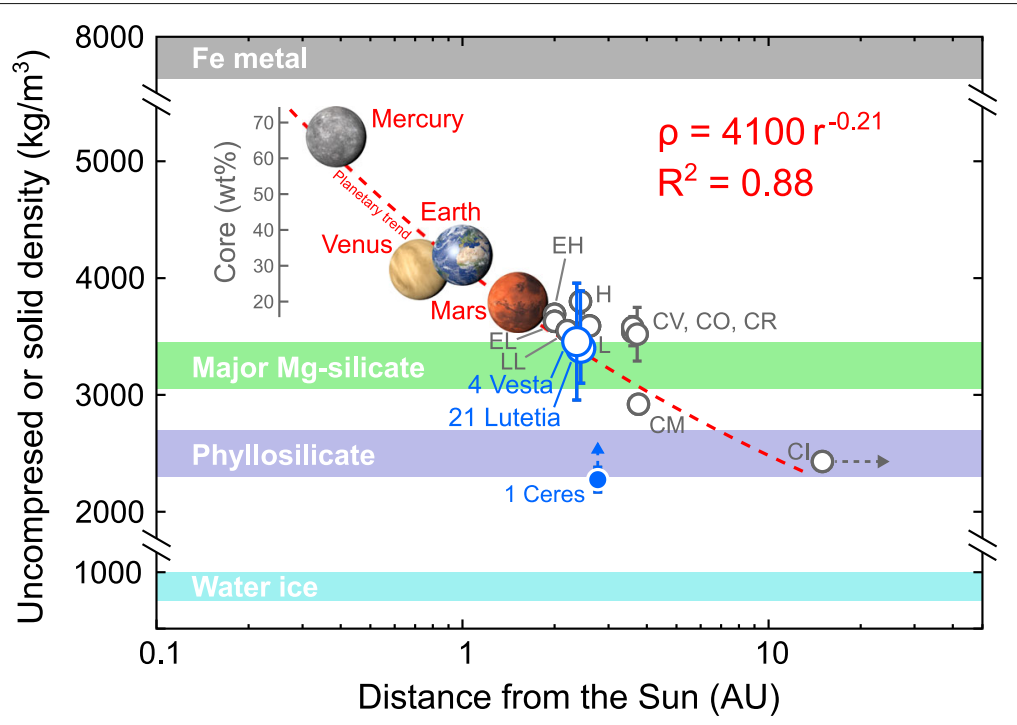

Fig. 4 Density of the rocky solar system bodies. Uncompressed and solid densities are shown for terrestrial planets and chondrites (gray), respectively. Bulk planetary densities are shown for asteroids (blue). For 1 Ceres, its bulk density is a lower limit of its solid density, given its high ice abundance and porosity. The red line shows a fit curve for the planets $\left(\rho=4100 r^{-0.21}\right)$. Data sources: density of planetary bodies are from Russell et al. (2012); Park et al. (2019); Sierks et al. (2011); Consolmagno et al. (2006); Macke et al. (2010); Macke et al. (2011); Britt and Consolmagno (2003); Lewis (1972); Stacey (2005); heliocentric distances of chondrite parent bodies are from Desch et al. (2018)

et al. 2013; Kruss and Wurm 2018). We highlight electromagnetic separation of magnetized micro-particles of Fe-Ni alloys (existing below their Curie point with a stable magnetic spin) from silicates (Harris and Tozer 1967; Larimer and Anders 1970) coupled with metal-oxide separation during chondrule formation as being effective segregation processes (e.g., Connolly Jr. et al. (2001)). Recently, Wurm et al. (2013) also observed that photophoretic separation enhances a metal-silicate fractionation. Thus, these physical fractionation processes likely occurred in the protoplanetary disk and may well explain the observed variations in $\mathrm{Fe} / \mathrm{O}, \mathrm{Fe} / \mathrm{Si}$, and $\mathrm{Fe} / \mathrm{Mg}$ in chondrites and terrestrial planets. The degree of sunward enrichment of magnetic micro-particles in the protoplanetary disk appears to scale radially with its magnetic field strength.

Paleomagnetic measurements of meteorites and their inclusions provide unique constraints on spatial and temporal changes of the magnetic field in the protoplanetary disk. Meteoritic records indicate the magnetic field intensity of $\sim 50 \mu \mathrm{T}$ at $2.5 \mathrm{AU}$ and $\sim 2 \mathrm{Myr}$ after the solar system initiation $\left(t_{0}\right)$ (Fu et al. 2014), whereas at 3-4 Myr after $t_{0}$, it weakens to $<20 \mu \mathrm{T}$ at 3-4 AU (Cournede et al. 2015; Desch et al. 2018). Finally, the nebular gas and thus its magnetic field deceased at $\sim 4$ Myr after $t_{0}$, as recorded by the volcanic achondrite angrite (Wang et al. 2017). These observations document a decrease in the nebular magnetic field strength with increasing heliocentric distance and time after $t_{0}$.
The terrestrial planets formed closer to the Sun compared to these meteorites and their components, given their present-day distributions. Chronological studies of planetary materials and planetary accretion models indicate that Earth and Mars grew rapidly within the first 2 Myr after $t_{0}$, although their final accretion continued for more than $10 \mathrm{Myr}$ (Kleine et al. 2009; Dauphas and Pourmand 2011). Early, rapid growth of the inner rocky planets is envisaged at locations closer to the Sun compared to meteorites and their constituents. Thus, it is likely that terrestrial planets formed under a stronger solar magnetic field compared to outer, younger meteoritic materials.

We show a correlation between the metallic core fraction and heliocentric distance for the terrestrial planets (Fig. 4). This trend is interpreted as resulting from spatial and temporal decays of magnetic field strength in the protoplanetary disk, which is consistent with paleomagnetic intensities recorded in meteorites (Bryson et al. 2020; Fu et al. 2020), magneto-hydrodynamic (MHD) disk models (Bai 2015), and accretion rates of stars (Wardle 2007).

Accretion rates for solar-mass stars in protoplanetary disks can have multi-Myr timescales $\left(\sim 10^{-9}\right.$ to $10^{-7} \mathrm{M}_{\odot}$ $\mathrm{yr}^{-1}$ ) (Hartmann et al. 2016). Collisional accretion, protoplanetary disk winds, and electromagnetic fields may control the evolution and dispersal of matter during the planet formation. The magnetic field strength $(B)$ in a protoplanetary disk should decrease with heliocentric distance. In addition, the azimuthal magnetic fields are likely to be strongest in the disk midplane (Bai 2017), the site of planetary accretion. The required $B$ to drive gas accretion 
onto the central star can be determined using equation 19 of Wardle (2007): where B $\sim 0.1-1 \times(r / \mathrm{au})^{(-1.25)} \mathrm{mT}$, assuming appropriate accretion rates. Using this equation, the estimated time averaged magnetic field strength during the planet formation in the presence of a protoplanetary disk is $\sim 0.3-3 \mathrm{mT}$ at Mercury, $\sim 0.1-1 \mathrm{mT}$ at the Earth, $\sim 3-300 \mu \mathrm{T}$ at $r=2.5 \mathrm{AU}$ (main belt asteroids), and $\sim 6-60 \mu \mathrm{T}$ at $r=10 \mathrm{AU}$. The latter two values are consistent with paleomagnetic measurements of the Semarkona meteorite (2.3 AU) by Fu et al. (2014) and the chondrite WIS 91600 (i.e. $10 \mathrm{AU}$, the putative initial formation location for WIS 91600, ungrouped C2 chondrite) reported by Bryson et al. (2020).

Kruss and Wurm (2018) suggested that enhanced growth of iron-rich dust aggregates in the inner region of protoplanetary disks leads to an iron gradient in the solar system. A corollary of this model is that planetary migration in the inner solar system did not disrupt this final result and that the Fe content can help us determine where and when an object was dominantly formed. The experiment carried out by Kruss and Wurm (2018) observed a critical magnetic field strength $(\sim 2 \mathrm{mT})$ where chains of magnetic grains start to form (their Fig. 9) due to stronger magnetic attraction relative to collisional repulsion. Later experiments by Kruss and Wurm (2020) observed chains of magnetic grains aggregating into clusters in a magnetic field above a given mass fraction of iron (their Fig. 10). These early experiments provide some support for forming mercury-type planets, but their results depended on the magnetic field strength and the mass fraction of iron. It is not clear if these experiments would only apply to regions around Mercury (where the magnetic fields are strongest), or extend out to the orbits of Earth and Mars.

Nebular gas carries the magnetic field in the protoplanetary disk. Metal-silicate segregation by solar magnetic forces is only effective before nebular gas dissipation (Kruss and Wurm 2020; Wang et al. 2017). Mercury's formation under reduced conditions in the presence of a gas disk with a strong magnetic field implies a $\tau_{\text {accretion }}$ age that is restricted to when a nebular envelope existed. Accretion in the presence of nebular gas is consistent with pebble accretion models of planetary formation, which may have contributed to the early formation of Mars and iron meteorite parent bodies (Johansen et al. 2015). Therefore, a key implication of our model is an early formation age ( $\sim 2$ Myr) for Mercury, comparable to that of Mars (Dauphas and Pourmand 2011; Yoshizaki and McDonough 2021). Furthermore, our model does not require a giant impact event and partial loss of its silicate shell for the origin of Mercury's large core (Benz et al. 2007; Asphaug and Reufer 2014).

Is our model applicable to exoplanetary systems? Unfortunately the database at present is not large enough to conduct a thorough assessment. TRAPPIST-1, our best documented exoplanetary system (i.e., 7 planets with $\mathrm{M}_{\oplus}$, $\mathrm{R}_{\oplus}$, and orbiting data), does not have a mercury-type planet. It is, however, an unusual system in that these planets are (1) close in (0.01 to $0.06 \mathrm{AU})$, (2) orbiting an ultra-cool, low mass, red dwarf $\operatorname{star}\left(\sim 0.09 \mathrm{M}_{\odot}\right)$, (3) their masses and radii are large relative to those of the star, and (4) they are predicted to have roughly similar compositional characteristics (Agol et al. 2021). The chemistry of this star is poorly understood, given its cool temperature. Thus, typical comparisons between these planets and their star composition cannot be completed.

Dense mercury-like exoplanets have been identified, but they are less common and often Earth-sized and larger objects (e.g., Santerne et al. (2018); Bonomo et al. (2019); Price and Rogers (2020); Schulze et al. (2021)). Interestingly, K2-229 b (0.6 days year ${ }^{-1}, 1.2 \mathrm{R}_{\oplus}$ and $\left.2.6 \mathrm{M}_{\oplus}\right)$ has a core mass fraction (70\%) equivalent to Mercury's, and its Fe-enrichment contrasts with its star's chemistry (Saterne et al. 2018). Several other Fe-rich exoplanets have been identified (e.g., see Table S5 in Schulze et al. 2021) many of which orbit close to their star that has a composition similar to our Sun's. Future exoplanetary observations will test this hypothesis of compositional fractionation in the protoplanetary disk by an evolving magnetic field and its control on planetary chemistry during accretion.

The potential for a habitable zone in an exoplanetary systems may be influenced by physical and chemical processes controlling the distribution of metal and silicate in an evolving protoplanetary disk. These processes can control the size and composition of a planet's core. The chemical equilibrium during accretion and metalsilicate differentiation reflects the local redox conditions and influences the amount of light elements partitioned into the core. In turn, these factors influence the stability and duration of the core's dynamo, which generates the planet's magnetosphere and serves to protect a yet unrealized biosphere. These factors, plus the distribution of some critical life supporting elements (e.g., 90\% of the Earth's phosphorus budget is in the core), are critical in establishing a planet's prospects for habitability.

\section{Conclusions}

We have developed compositional models for the terrestrial planets that takes note of their chemical differences as a function of their heliocentric positions. The presence and size of their metallic cores depends on the redox environment in the protoplanetary disk and the planet's mass fraction of accreted metal alloys, the latter of which is controlled by electromagnetic processing in the disk. We use the measured K/Th values of the terrestrial planets to estimate its volatile element inventory (e.g., bulk sulfur content). The redox condition during core formation, controls the identity and amount of light elements in the core (e.g., S, Si, O). These light elements significantly 
lower the core's solidus and extends its molten-state lifetime. Collectively, these factors contribute to convection in a molten core and dynamo action.

These attributes of our solar system may be equally applicable to exoplanetary systems. The generation of a planetary magnetosphere, which nurtures life, shapes a planet's habitability. It is likely that life's sustainability critically depends on being sited in the Goldilocks zone and having the right amount of metallic core, which contains an appropriate amount of a light element and is not cooling too fast.

\section{Acknowledgements}

We thank many our colleagues, particularly T. Kakegawa, E. Ohtani, N. Chabot, V. Lekic, and R. Ash, who have listened to various versions of this project and given helpful comments. We are very grateful to the editor and the two anonymous reviewers who offered significant improvements to our manuscript.

\section{Authors' contributions}

WFM and TY proposed and conceived various portions of this study and together calculated the compositional models. The manuscript was written by WFM, with edits, discussions, and revisions by TY and WFM. Both authors read and approved the final manuscript.

\section{Funding}

This work was supported by NSF grant (EAR1650365) to WFM, and the JSPS KAKENHI Grant (JP18J20708), the GP-EES research grant and DIARE grant to TY.

\section{Availability of data and materials}

Correspondence and requests for materials should be addressed to WFM.

\section{Declarations}

\section{Competing interests}

The authors declare that they have no competing interest.

Received: 17 December 2020 Accepted: 17 May 2021

Published online: 02 July 2021

\section{References}

Agol E, Dorn C, Grimm SL, Turbet M, Ducrot E, Delrez L, Gillon M, Demory B-O, Burdanov A, Barkaoui K, et al (2021) Refining the transit-timing and photometric analysis of TRAPPIST-1: masses, radii, densities, dynamics, and ephemerides. Planet Sci J 2(1):1

Aitta A (2012) Venus' internal structure, temperature and core composition. Icarus 218(2):967-974. http://dx.doi.org/10.1016/j.icarus.2012.01.007

Alexander CMO (2019) Quantitative models for the elemental and isotopic fractionations in chondrites: The carbonaceous chondrites. Geochim Cosmochim Acta 254:277-309. http://dx.doi.org/10.1016/j.gca.2019.02.008

Alexander CMO (2019) Quantitative models for the elemental and isotopic fractionations in the chondrites: The non-carbonaceous chondrites. Geochim Cosmochim Acta 254:246-276. http://dx.doi.org/10.1016/j.gca. 2019.01.026

Arevalo Jr. R, McDonough WF, Luong M (2009) The K/U ratio of the silicate Earth: Insights into mantle composition, structure and thermal evolution. Earth Planet Sci Lett 278(3-4):361-369. http://dx.doi.org/10.1016/j.epsl. 2008.12.023

Asphaug E (2014) Impact origin of the Moon? Ann Rev Earth Planet Sci 42:551-578. http://dx.doi.org/10.1146/annurev-earth-050212-124057

Asphaug E, Reufer A (2014) Mercury and other iron-rich planetary bodies as relics of inefficient accretion. Nat Geosci 7(8):564-568. http://dx.doi.org/10. 1038/NGEO2189

Asplund M, Grevesse N, Sauval AJ, Scott P (2009) The chemical composition of the Sun. Annu Rev Astron Astrophys 47:481-522. http://dx.doi.org/10. 1146/annurev.astro.46.060407.145222
Bai X-N (2015) Hall effect controlled gas dynamics in protoplanetary disks. II. Full 3D simulations toward the outer disk. Astrophys J 798(2):84. http://dx. doi.org/10.1088/0004-637X/798/2/84

Bai X-N (2017) Wind-Driven Global Evolution of Protoplanetary Disks. In: Pessah M, Gressel O (eds). Formation, Evolution, and Dynamics of Young Solar Systems. Astrophysics and Space Science Library, vol 445. Springer, Cham. pp 63-90. https://doi.org/10.1007/978-3-319-60609-5_3

Benz W, Anic A, Horner J, Whitby J (2007) The Origin of Mercury. Space Sci Rev 132(2):189-202. http://dx.doi.org/10.1007/s11214-007-9284-1

Benz W, Slattery WL, Cameron AGW (1988) Collisional stripping of Mercury's mantle. Icarus 74(3):516-528. http://dx.doi.org/10.1016/00191035(88)90118-2

Bischoff A, Palme H, Schultz L, Weber D, Weber HW, Spettel B (1993) Acfer 182 and paired samples, an iron-rich carbonaceous chondrite: Similarities with ALH85085 and relationship to CR chondrites. Geochim Cosmochim Acta 57(11):2631-2648. http://dx.doi.org/10.1016/0016-7037(93)90422-S

Bonomo AS, Zeng L, Damasso M, et al. (2019) A giant impact as the likely origin of different twins in the Kepler-107 exoplanet system. Nat Astron 3:416-423. https://doi.org/10.1038/s41550-018-0684-9

Boss AP (1998) Temperatures in protoplanetary disks. Ann Rev Earth Planet Sci 26(1):53-80. http://dx.doi.org/10.1146/annurev.earth.26.1.53

Boujibar A, Habermann M, Righter K, Ross DK, Pando K, Righter M, Chidester BA, Danielson LR (2019) U, Th, and K partitioning between metal, silicate, and sulfide and implications for Mercury's structure, volatile content, and radioactive heat production. Am Mineral 104(9):1221-1237. http://dx.doi. org/10.2138/am-2019-7000

Braukmüller N, Wombacher F, Funk C, Münkers C (2019) Earth's volatile element depletion pattern inherited from a carbonaceous chondrite-like source. Nat Geosci 12(7):564-568. http://dx.doi.org/10.1038/s41561-019-0375-x

Britt DT, Consolmagno GJSJ (2003) Stony meteorite porosities and densities: A review of the data through 2001. Meteorit Planet Sci 38(8):1161-1180. http://dx.doi.org/10.1111/j.1945-5100.2003.tb00305.x

Bryson JFJ, Weiss BP, Biersteker JB, King AJ, Russell SS (2020) Constraints on the distances and timescales of solid migration in the early solar system from meteorite magnetism. Astrophys J 896(2):103. http://dx.doi.org/10.3847/ 1538-4357/ab91ab

Cameron AGW, Fegley Jr. B, Benz W, Slattery WL (1988) The strange density of Mercury: Theoretical considerations. In: Vilas F, Chapman C, Matthews MS (eds). Mercury. University of Arizona Press, Tucson. pp 692-708

Connolly Jr. HC, Huss GR, Wasserburg GJ (2001) On the formation of Fe-Ni metal in Renazzo-like carbonaceous chondrites. Geochim Cosmochim Acta 65(24):4567-4588. http://dx.doi.org/10.1016/S0016-7037(01)00749-9

Consolmagno GJ, Macke RJ, Rochette P, Britt DT, Gattacceca J (2006) Density, magnetic susceptibility, and the characterization of ordinary chondrite falls and showers. Meteorit Planet Sci 41(3):331-342. http://dx.doi.org/10.1111/ j.1945-5100.2006.tb00466.x

Cournede C, Gattacceca J, Gounelle M, Rochette P, Weiss BP, Zanda B (2015) An early solar system magnetic field recorded in CM chondrites. Earth Planet Sci Lett 410:62-74. http://dx.doi.org/10.1016/j.epsl.2014.11.019

Dauphas N (2017) The isotopic nature of the Earth's accreting material through time. Nature 541(7638):521-524. http://dx.doi.org/10.1038/nature20830

Dauphas N, Pourmand A (2011) Hf-W-Th evidence for rapid growth of Mars and its status as a planetary embryo. Nature 473(7348):489-492. http://dx. doi.org/10.1038/nature10077

Desch SJ, Kalyaan A, Alexander CMO (2018) The effect of Jupiter's formation on the distribution of refractory elements and inclusions in meteorites. Astrophys J Suppl Ser 238(1):11. http://dx.doi.org/10.3847/1538-4365/ aad95f

Dumoulin C, Tobie G, Verhoeven O, Rosenblatt P, Rambaux N (2017) Tidal constraints on the interior of Venus. J Geophys Res Planets 122(6):1338-1352. http://dx.doi.org/10.1002/2016JE005249

Ebel DS, Alexander CMO (2011) Equilibrium condensation from chondritic porous IDP enriched vapor: Implications for Mercury and enstatite chondrite origins. Planet Space Sci 59(15):1888-1894. http://dx.doi.org/10. 1016/j.pss.2011.07.017

Fu RR, Kehayias P, Weiss BP, Schrader DL, Bai X-N, Simon JB (2020) Weak magnetic fields in the outer solar nebula recorded in CR chondrites. J Geophys Res Planets 125(5):2019JE006260. http://dx.doi.org/10.1029/ 2019JE006260

Fu RR, Weiss BP, Lima EA, Harrison RJ, Bai X-N, Desch SJ, Ebel DS, Suavet C, Wang $H$, Glenn D, et al (2014) Solar nebula magnetic fields recorded in the Semarkona meteorite. Science 346(6213):1089-1092. http://dx.doi.org/10. 1126/science. 1258022 
Gosselin DC, Laul JC (1990) Chemical characterization of a unique chondrite: Allan Hills 85085. Meteoritics 25(2):81-87. http://dx.doi.org/10.1111/j.19455100.1990.tb00979.x

Harris PG, Tozer DC (1967) Fractionation of iron in the Solar system. Nature 215(5109):1449-1451. http://dx.doi.org/10.1038/2151449a0

Hartmann L, Herczeg G, Calvet N (2016) Accretion onto pre-main-sequence stars. Annu Rev Astron Astrophys 54:135-180

Hutson M, Ruzicka A (2000) A multi-step model for the origin of E3 (enstatite) chondrites. Meteorit Planet Sci 35(3):601-608. http://dx.doi.org/10.1111/j. 1945-5100.2000.tb01440.x

Ivanova MA, Kononkova NN, Krot AN, Greenwood RC, Franchi IA, Verchovsky AB, Trieloff M, Korochantseva EV, Brandstätter F (2008) The Isheyevo meteorite: Mineralogy, petrology, bulk chemistry, oxygen, nitrogen, carbon isotopic compositions, and ${ }^{40} \mathrm{Ar}-{ }^{39} \mathrm{Ar}$ ages. Meteorit Planet Sci 43(5):915-940. http://dx.doi.org/10.1111/j.1945-5100.2008.tb01090.x

Johansen A, Mac Low M-M, Lacerda P, Bizzarro M (2015) Growth of asteroids, planetary embryos, and Kuiper belt objects by chondrule accretion. Sci Adv 1(3):1500109. http://dx.doi.org/10.1126/sciadv.1500109

Kerridge J (1979) Fractionation of refractory lithophile elements among chondritic meteorites. In: Lunar and Planetary Science Conference Proceedings Vol. 10. pp 989-996

Kleine T, Touboul M, Bourdon B, Nimmo F, Mezger K, Palme H, Jacobsen SB, Yin Q-Z, Halliday AN (2009) Hf-W chronology of the accretion and early evolution of asteroids and terrestrial planets. Geochim Cosmochim Acta 73(17):5150-5188. http://dx.doi.org/10.1016/j.gca.2008.11.047

Krähenbühl U, Morgan JW, Ganapathy R, Anders E (1973) Abundance of 17 trace elements in carbonaceous chondrites. Geochim Cosmochim Acta 37(5):1353-1370. http://dx.doi.org/10.1016/0016-7037(73)90066-5

Kruijer TS, Burkhardt C, Budde G, Kleine T (2017) Age of Jupiter inferred from the distinct genetics and formation times of meteorites. Proc Natl Acad Sci 114(26):6712-6716. http://dx.doi.org/10.1073/pnas.1704461114

Kruss M, Wurm G (2018) Seeding the Formation of Mercurys: An Iron-sensitive Bouncing Barrier in Disk Magnetic Fields. Astrophys J 869(1):45. http://dx. doi.org/10.3847/1538-4357/aaec78

Kruss M, Wurm G (2020) Composition and size dependent sorting in preplanetary growth: seeding the formation of Mercury-like planets. Planet Sci J 1(1):23. http://dx.doi.org/10.3847/PSJ/ab93c4

Larimer JW (1979) The condensation and fractionation of refractory lithophile elements. Icarus 40(3):446-454. http://dx.doi.org/10.1016/00191035(79)90038- 1

Larimer JW, Anders E (1970) Chemical fractionations in meteorites-III. Major element fractionations in chondrites. Geochim Cosmochim Acta 34(3):367-387. http://dx.doi.org/10.1016/0016-7037(70)90112-2

Leitch CA, Smith JV (1982) Petrography, mineral chemistry and origin of Type I enstatite chondrites. Geochim Cosmochim Acta 46(11):2083-2097. http:// dx.doi.org/10.1016/0016-7037(82)90187-9

Lewis JS (1972) Metal/silicate fractionation in the solar system. Earth Planet Sci Lett 15(3):286-290. http://dx.doi.org/10.1016/0012-821X(72)90174-4

Lodders K (2003) Solar system abundances and condensation temperatures of the elements. Astrophys J 591(2):1220-1247. http://dx.doi.org/10.1086/ 375492

Lodders K (2020) Solar Elemental Abundances. In: Read P (ed). Oxford Research Encyclopedia of Planetary Science. Oxford University Press, Oxford. pp 1-68. http://dx.doi.org/10.1093/acrefore/9780190647926.013.145

Lodders K, Fegley Jr. B (1998) The Planetary Scientist's Companion. Oxford University Press, New York

Macke RJ, Consolmagno GJ, Britt DT (2011) Density, porosity, and magnetic susceptibility of carbonaceous chondrites. Meteorit Planet Sci 46(12):1842-1862. http://dx.doi.org/10.1111/j.1945-5100.2011.01298.x

Macke RJ, Consolmagno GJ, Britt DT, Hutson ML (2010) Enstatite chondrite density, magnetic susceptibility, and porosity. Meteorit Planet Sci 45(9):1513-1526. http://dx.doi.org/10.1111/j.1945-5100.2010.01129.x

Margot J-L, Hauck I, Steven A, Mazarico E, Padovan S, Peale SJ (2018) Mercury's internal structure. In: Solomon SC, Nittler LR, Anderson BJ (eds). Mercury: The View After MESSENGER. Cambridge University Press, Cambridge. pp 85-113. http://dx.doi.org/10.1017/9781316650684.005

McCall GJH (1968) The Bencubbin meteorite: Further details, including microscopic character of host material and two chondrite enclaves. Mineral Mag J Mineral Soc 36(281):726-739. http://dx.doi.org/10.1180/ minmag.1968.036.281.14

McDonough WF (2014) Compositional model for the Earth's core. In: Holland HD, Turekian KK (eds). Treatise on Geochemistry (Second Edition). Elsevier,
Oxford Vol. 3. pp 559-577. http://dx.doi.org/10.1016/B978-0-08-095975-7. 00215-1

McDonough WF, Sun S-S (1995) The composition of the Earth. Chem Geol 120(3-4):223-253. http://dx.doi.org/10.1016/0009-2541(94)00140-4

McDonough WF, Šrámek O, Wipperfurth SA (2020) Radiogenic power and geoneutrino luminosity of the Earth and other terrestrial bodies through time. Geochem Geophys Geosyst 21(7):2019GC008865. http://dx.doi.org/ 10.1029/2019GC008865

McKee CF, Ostriker EC (2007) Theory of star formation. Annu Rev Astron Astrophys 45:565-687. http://dx.doi.org/10.1146/annurev.astro.45.051806. 110602

Namur O, Charlier B, Holtz F, Cartier C, McCammon C (2016) Sulfur solubility in reduced mafic silicate melts: Implications for the speciation and distribution of sulfur on Mercury. Earth Planet Sci Lett 448:102-114. http:// dx.doi.org/10.1016/j.epsl.2016.05.024

Nittler LR, Chabot NL, Grove TL, Peplowski PN (2018) The Chemical Composition of Mercury. In: Solomon SC, Nittler LR, Anderson BJ (eds). Mercury: The View After MESSENGER. Cambridge University Press, Cambridge. pp 30-51. http://dx.doi.org/10.1017/9781316650684. 00310.1017/9781316650684.003

Park RS, Vaughan AT, Konopliv AS, Ermakov Al, Mastrodemos N, Castillo-Rogez JC, Joy SP, Nathues A, Polanskey CA, Rayman MD, Riedel JE, Raymond CA, Russell CT, Zuber MT (2019) High-resolution shape model of Ceres from stereophotoclinometry using Dawn imaging data. Icarus 319:812-827. http://dx.doi.org/10.1016/j.icarus.2018.10.024

Pasek MA, Milsom JA, Ciesla FJ, Lauretta DS, Sharp CM, Lunine JI (2005) Sulfur chemistry with time-varying oxygen abundance during Solar System formation. Icarus 175(1):1-14. http://dx.doi.org/10.1016/j.icarus.2004.10. 012

Peplowski PN, Evans LG, Hauck SA, McCoy TJ, Boynton WV, Gillis-Davis JJ, Ebel DS, Goldsten JO, Hamara DK, Lawrence DJ, McNutt RL, Nittler LR, Solomon SC, Rhodes EA, Sprague AL, Starr RD, Stockstill-Cahill KR (2011) Radioactive elements on Mercury's surface from MESSENGER: Implications for the planet's formation and evolution. Science 333(6051):1850-1852. http://dx. doi.org/10.1126/science.1211576

Price EM, Rogers LA (2020) Tidally distorted, iron-enhanced exoplanets closely orbiting their stars. Astrophys J 894(1):8

Righter K, Sutton SR, Danielson L, Pando K, Newville M (2016) Redox variations in the inner solar system with new constraints from vanadium XANES in spinels. Am Mineral 101(9):1928-1942. http://dx.doi.org/10.2138/am2016-5638

Ringwood AE (1961) Silicon in the metal phase of enstatite chondrites and some geochemical implications. Geochim Cosmochim Acta 25(1):1-13. http://dx.doi.org/10.1016/0016-7037(61)90056-4

Rubie DC, Frost DJ, Mann U, Asahara Y, Nimmo F, Tsuno K, Kegler P, Holzheid A Palme H (2011) Heterogeneous accretion, composition and core-mantle differentiation of the Earth. Earth Planet Sci Lett 301(1):31-42. http://dx.doi. org/10.1016/j.epsl.2010.11.030

Russell CT, Raymond CA, Coradini A, McSween HY, Zuber MT, Nathues A, De Sanctis MC, Jaumann R, Konopliv AS, Preusker F, Asmar SW, Park RS Gaskell R, Keller HU, Mottola S, Roatsch T, Scully JEC, Smith DE, Tricarico P, Toplis MJ, Christensen UR, Feldman WC, Lawrence DJ, McCoy TJ, Prettyman TH, Reedy RC, Sykes ME, Titus TN (2012) Dawn at Vesta: Testing the protoplanetary paradigm. Science 336(6082):684-686. http://dx.doi. org/10.1126/science.1219381

Santerne A, Brugger B, Armstrong DJ, Adibekyan V, Lillo-Box J, Gosselin H, Aguichine A, Almenara J-M, Barrado D, Barros SCC, Bayliss D, Boisse I, Bonomo AS, Bouchy F, Brown DJA, Deleuil M, Delgado Mena E, Demangeon O, Díaz RF, Doyle A, Dumusque X, Faedi F, Faria JP, Figueira P, Foxell E, Giles H, Hébrard G, Hojjatpanah S, Hobson M, Jackman J, King G, Kirk J, Lam KWF, Ligi R, Lovis C, Louden T, McCormac J, Mousis O, Neal JJ, Osborn HP, Pepe F, Pollacco D, Santos NC, Sousa SG, Udry S, Vigan A (2018) An Earth-sized exoplanet with a Mercury-like composition. Nat Astron 2(5):393. http://dx.doi.org/10.1038/s41550-018-0420-5

Schubert G, Ross MN, Stevenson DJ, Spohn T (1988) Mercury's thermal history and the generation of its magnetic field. In: Vilas F, Chapman C, Matthews MS (eds). Mercury. University of Arizona Press, Tucson. pp 429-460

Schulze J, Wang J, Johnson J, Unterborn C, Panero W (2021) The probability that a rocky planet's composition reflects its host star. Planet Sci J. https:// iopscience.iop.org/article/10.3847/PSJ/abcaa8 
See $V$, Jardine M, Vidotto AA, Petit P, Marsden SC, Jeffers SV, do Nascimento JD (2014) The effects of stellar winds on the magnetospheres and potential habitability of exoplanets. Astron Astrophys 570:99. http://dx.doi.org/10. 1051/0004-6361/201424323

Sierks H, Lamy P, Barbieri C, Koschny D, Rickman H, Rodrigo R, A'Hearn MF, Angrilli F, Barucci MA, Bertaux J-L, Bertini I, Besse S, Carry B, Cremonese G, Da Deppo V, Davidsson B, Debei S, De Cecco M, De Leon J, Ferri F, Fornasier S, Fulle M, Hviid SF, Gaskell RW, Groussin O, Gutierrez P, Ip W, Jorda L, Kaasalainen M, Keller HU, Knollenberg J, Kramm R, Kührt E, Küppers M, Lara L, Lazzarin M, Leyrat C, Moreno JJL, Magrin S, Marchi S, Marzari F, Massironi M, Michalik H, Moissl R, Naletto G, Preusker F, Sabau L, Sabolo W, Scholten F, Snodgrass C, Thomas N, Tubiana C, Vernazza P, Vincent J-B, Wenzel K-P, Andert T, Pätzold M, Weiss BP (2011) Images of asteroid 21 Lutetia: a remnant planetesimal from the early Solar System. Science 334(6055):487-490. http://dx.doi.org/10.1126/science.1207325

Sohl F, Schubert G (2015) Interior Structure, Composition, and Mineralogy of the Terrestrial Planets. In: Schubert G (ed). Treatise on Geophysics (Second Edition). Elsevier, Oxford Vol. 10. pp 23-64. http://dx.doi.org/10.1016/B9780-444-53802-4.00166-4

Stacey FD (2005) High pressure equations of state and planetary interiors. Rep Prog Phys 68(2):341. http://dx.doi.org/10.1088/0034-4885/68/2/R03

Surkov YA, Kirnozov FF, Glazov VN, Dunchenko AG, Tatsy LP, Sobornov OP (1987) Uranium, thorium, and potassium in the Venusian rocks at the landing sites of Vega 1 and 2.J Geophys Res Solid Earth 92(B4):537-540. http://dx.doi.org/10.1029/JB092iB04p0E537

Takahashi H, Janssens M-J, Morgan JW, Anders E (1978) Further studies of trace elements in C3 chondrites. Geochim Cosmochim Acta 42(1):97-106. http://dx.doi.org/10.1016/0016-7037(78)90220-X

Taylor GJ, Boynton W, Brückner J, Wänke H, Dreibus G, Kerry K, Keller J, Reedy R, Evans L, Starr R, Squyres S, Karunatillake S, Gasnault O, Maurice S, d'Uston C, Englert P, Dohm J, Baker V, Hamara D, Janes D, Sprague A, Kim K, Drake D (2006) Bulk composition and early differentiation of Mars. J Geophys Res Planets 111(E03S10):03-10. http://dx.doi.org/10.1029/2005JE002645

Tosi N, Grott M, Plesa A-C, Breuer D (2013) Thermochemical evolution of Mercury's interior. J Geophys Res Planets 118(12):2474-2487. http://dx.doi. org/10.1002/jgre.20168

Urey HC, Craig H (1953) The composition of the stone meteorites and the origin of the meteorites. Geochim Cosmochim Acta 4(1-2):36-82. http:// dx.doi.org/10.1016/0016-7037(53)90064-7

Wang H, Weiss BP, Bai X-N, Downey BG, Wang J, Wang J, Suavet C, Fu RR, Zucolotto ME (2017) Lifetime of the solar nebula constrained by meteorite paleomagnetism. Science 355(6325):623-627. http://dx.doi.org/10.1126/ science.aaf5043

Wänke H (1981) Constitution of terrestrial planets. Philos Trans R Soc Ser A Math Phys Sci 303(1477):287-302. http://dx.doi.org/10.1098/rsta.1981.0203

Wardle M (2007) Magnetic fields in protoplanetary disks. Astrophys Space Sci 311(1-3):35-45. http://dx.doi.org/10.1007/s10509-007-9575-8

Warren PH (2011) Stable-isotopic anomalies and the accretionary assemblage of the Earth and Mars: A subordinate role for carbonaceous chondrites. Earth Planet Sci Lett 311(1):93-100. http://dx.doi.org/10.1016/j.epsl.2011. 08.047

Wasson JT (1988) The building stones of the planets. In: Vilas F, Chapman CR, Matthews MS (eds). Mercury. University of Arizona Press, Tucson. pp 622-650

Wasson JT, Kallemeyn GW (1988) Compositions of chondrites. Philos Trans R Soc A Math Phys Eng Sci 325(1587):535-544. http://dx.doi.org/10.1098/ rsta.1988.0066

Wasson JT, Kallemeyn GW (1990) Allan Hills 85085: A subchondritic meteorite of mixed nebular and regolithic heritage. Earth Planet Sci Lett 101(2-4):148-161. http://dx.doi.org/10.1016/0012-821X(90)90150-V

Weidenschilling SJ (1978) Iron/silicate fractionation and the origin of Mercury. Icarus 35(1):99-111. http://dx.doi.org/10.1016/0019-1035(78)90064-7

Weisberg MK, Kimura M (2012) The unequilibrated enstatite chondrites. Chem Erde-Geochem 72(2):101-115. http://dx.doi.org/10.1016/j.chemer.2012.04. 003

Williams JP, Cieza LA (2011) Protoplanetary disks and their evolution. Annu Rev Astron Astrophys 49:67-117. http://dx.doi.org/10.1146/annurev-astro081710-102548

Wood JA (2005) The chondrite types and their origins. In: Krot AN, Scott ERD, Reipurth B (eds). Chondrites and the Protoplanetary Disk. Astronomical Society of the Pacific, San Francisco Vol. 341. pp 953-971
Wurm G, Trieloff M, Rauer H (2013) Photophoretic separation of metals and silicates: The formation of Mercury-like planets and metal depletion in chondrites. Astrophys J 769(1):78. http://dx.doi.org/10.1088/0004-637X/ 769/1/78

Yoshizaki T, Ash RD, Lipella MD, Yokoyama T, McDonough WF (2021) Variable refractory lithophile element compositions of planetary building blocks. Geochim Cosmochim Acta. https://doi.org/10.1016/j.gca.2021.05.057

Yoshizaki T, McDonough WF (2021) Earth and MarsÜdistinct inner solar system products. Geochemistry 125746. https://doi.org/10.1016/j.chemer.2021. 125746

Yoshizaki T, McDonough WF (2020) The composition of Mars. Geochim Cosmochim Acta 273:137-162. http://dx.doi.org/10.1016/j.gca.2020.01.011

\section{Publisher's Note}

Springer Nature remains neutral with regard to jurisdictional claims in published maps and institutional affiliations.

\section{Submit your manuscript to a SpringerOpen ${ }^{\circ}$ journal and benefit from:}

- Convenient online submission

Rigorous peer review

- Open access: articles freely available online

- High visibility within the field

- Retaining the copyright to your article

Submit your next manuscript at $>$ springeropen.com 